\title{
A Scientometric Review of Digital Currency and Electronic Payment Research: A Network Perspective
}

\author{
Qing Shi and Xiaoqi Sun (i) \\ The Institute for China's Overseas Interests, Shenzhen University, Shenzhen, Guangdong 518060, China \\ Correspondence should be addressed to Xiaoqi Sun; sunxiaoqi@szu.edu.cn
}

Received 1 September 2020; Revised 1 October 2020; Accepted 18 October 2020; Published 9 November 2020

Academic Editor: Xueyong Liu

Copyright ( 2020 Qing Shi and Xiaoqi Sun. This is an open access article distributed under the Creative Commons Attribution License, which permits unrestricted use, distribution, and reproduction in any medium, provided the original work is properly cited.

\begin{abstract}
The potential implications of digital currencies and electronic payment (DC/EP) have become a hot global research area. To present the knowledge bases and research fronts of this field, we apply a scientometric approach to analyze 454 publications obtained from the Web of Science core collection. Results show that, first, the knowledge bases can be classified into three main topics: (1) the usage and diversification effect of private digital currencies from the point of investment and asset allocation; (2) the price dynamics and market efficiency of private digital currencies; and (3) other economic roles of digital currencies and corresponding change brought into the monetary system. Second, several research trends can be inferred using sliding window analysis and burst detection, namely, how the introduction of digital currencies changes consumers' choice in payment instrument and their money demand; how social media and investor sentiment affect the market of digital currencies; and the impact of digital currencies on the central bank, monetary policy, and central bank digital currency. Third, core scholars and countries involved in the research of DC/EP are identified, and it is found that collaboration has been rising especially among European scholars and countries. With these systematic analyses, we offer recommendations for scholars and practitioners in future research of DC/EP.
\end{abstract}

\section{Introduction}

The global spread and use of the Internet and mobile phones contribute to the development of new forms of money and financial payments $[1,2]$. Specifically, digital currencies and electronic payments (DC/EP) are introduced to conduct convenient and effective financial transactions. Digital currencies, or digital money, are referred to as any types of currencies using FinTech, which include cryptocurrencies issued by private entities, central bank digital currencies, and other forms of digital money, while electronic payments are referred to as the payments using digital instruments such as mobile wallets. These financial innovations, which bring a range of impacts on various aspects of financial markets and the wider economy, have drawn increasing attention from academia, enterprises, and governments and become a hot global research topic $[3,4]$.
The employment of DC/EP has been facilitated by the innovation of blockchain based on the decentralized ledger technology (DLT), which promises to offer secured peer-topeer transactions and auditable and transparent transfer of assets, thus reducing the trust gap $[5,6]$. The applications of DC/EP are multitude. It benefits consumers and merchants through more efficient and less expensive services for e-commerce and cross-border payments [7-9]. Also, some types of digital currencies can be potentially used as alternative investment instruments $[10,11]$. Moreover, besides private end-users, DC/EP may provide central banks and the banking industry with additional monetary policy tools $[12-14]$. And the regulation society may also rely on the data generated by DC/EP for filtering and signal extraction, such as intelligent auditing, tracing functionality, and promoting cooperation among regulatory agencies [15]. Nonetheless, potential risks and disruptions may arise with regard to 
business models, financial systems, and regulation regimes [16-18].

Given the rising importance of DC/EP initiatives, a review study is demanded. There exist some survey works on the related literature. For example, Bohme et al. [19] reviewed the economics, technology, and governance of Bitcoin. Tschorsch and Scheuermann [20] carried out a review on the protocol and building blocks under decentralized digital currencies and explored the design space as well as fundamental structures at the core of the protocol. Holub and Johnson [21] and Corbet et al. [22] reviewed the literature on cryptocurrencies. Dashkevich et al. [23] performed a survey on the applications of blockchain technology to functions by the central bank. The existing literature reviews adopted a descriptive statistical approach to analyze the frequency and distributions of knowledge units and investigate the context of critical articles, however, ignoring the structure features embodied in the network of knowledge units and its potential change. Through scientometric methods, we aim to reveal the structure features of DC/EP knowledge networks, including cocitation network, cooccurrence network, and collaboration network, thereby providing a roadmap for prospective scholars in this field.

A CiteSpace study typically consists of several components, notably a body of scientific literature which is obtained through the objective criteria of selection and exclusion, a set of scientometric metrics and visual analytic tools that can highlight significant patterns and trends, and theories that guide the interpretation of visualized intellectual structures and dynamic patterns [24]. Scientometric methods include author cocitation analysis (ACA) [25], document cocitation analysis (DCA) [26], coword analysis [27], and many other variations. Compared to traditional reviews, a scientometric review has the advantages of dealing with big data, providing a more rigorous research output, finding pivotal points in an intellectual structure, detecting the emerging trends in a specific field, and employing various network-based visualization technologies to make a more intuitive impression [23, 28, 29]. Therefore, this approach has become increasingly applied in different areas of academic research, such as identifying the research trends on green construction [30], showing the intellectual landscape of propoor tourism research [31], finding the opportunities and challenges in destination branding [32], mapping the evolution and research framework of carbon footprint [33], and arising number of scientometric studies in the fields of finance and economics $[34,35]$. These papers demonstrate the advantage and fitness of scientometric methods for exploring academic knowledge bases and corresponding cutting-edge issues. Despite the popularity of scientometric methods, to our knowledge, a few publications have applied it to analyze the rapidly rising literature in the area of $\mathrm{DC} /$ $\mathrm{EP}$, neither to visualize the knowledge base nor to detect the research frontiers. Our work is thus to fill this gap.

To sum up, this paper makes two contributions to the literature by using the scientometric approach and CiteSpace. First, we use a new review method to investigate the DC/EP related studies, which systematically explore and visualize the knowledge bases, intellectual structure, and emerging hot topics and research fronts in the area of DC/ EP. Second, we extend the application of CiteSpace to a new literature field, that is, DC/EP research.

The remainder of this paper is organized as follows. Section 2 illustrates the scientometric research method, including network construction, network-related metrics, parameter setting in the CiteSpace, and data sources. Section 3 uses CiteSpace network analysis to explore the intellectual structure of DC/EP through clustering analysis of citations and timeline mapping of its evolutionary path. Section 4 conducts sliding window analysis and citation bursts detection to demonstrate structural changes of cocitation networks and find probable bursts of research interest followed by a clustering analysis of terms and keywords to further analyze the emerging hot topics and research fronts. Section 5 investigates core scholars and countries through clustering analysis and maps the collaboration network to highlight the major strength in the field of DC/EP. The last section is the concluding part.

\section{Methodology and Data}

2.1. Network Construction. Network analysis is one of the foundations of the CiteSpace studies. The network consists of nodes and edges linking these nodes. In matrix language, one network can be expressed as the following equation:

$$
G^{v}=\left[\begin{array}{cccc}
e_{11}^{v} & e_{12}^{v} & \cdots & e_{1 n}^{v} \\
e_{21}^{v} & e_{22}^{v} & \cdots & e_{2 n}^{v} \\
\vdots & \vdots & \ddots & \vdots \\
e_{n 1}^{v} & e_{n 2}^{v} & \cdots & e_{\mathrm{nn}}^{v}
\end{array}\right],
$$

where $e_{i j}^{v}$ denotes the connection between node $i$ and node $j$ of network type $v$, which is defined by the node type. For citing references, if two nodes show simultaneously in the same reference, then these two nodes are connected, that is, $e_{i j}>0$; otherwise $e_{i j}=0$. The value of $e_{i j}$ is called the weight of the edge. The more two nodes show together, the larger $e_{i j}$ is. For cited references, two nodes are connected if both are cited simultaneously by one reference, that is, $e_{i j}>0$. In other words, the network is weighted but undirected network. Figure 1 is an example illustration for the network construction.

For citing references, we construct four networks in which authors, countries, terms, and keywords are set as nodes, respectively. The author network is used to analyze collaboration between authors and to identify key authors in the network using centrality indicators; the country network is constructed to investigate the collaboration between countries; and the keyword network can identify the current hot topics and previous hot topics.

For cited references, we construct a cocitation network in which cited references are set as nodes. Through cocitation network, we reveal the intellectual structure of DC/EP by analyzing clusters and key nodes and learn the evolution of research fronts and knowledge bases and the critical articles in the evolution process. 


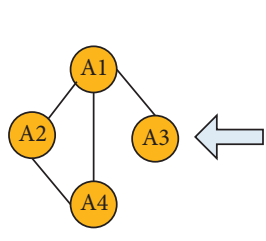

(a)

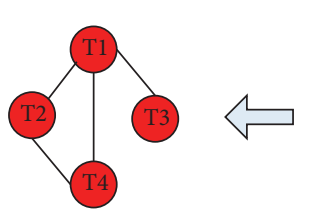

(e)

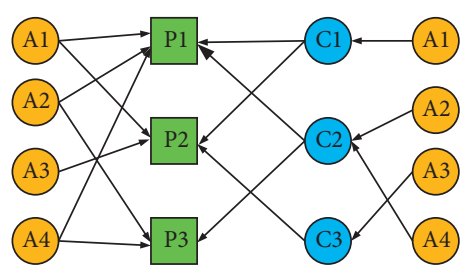

(b)

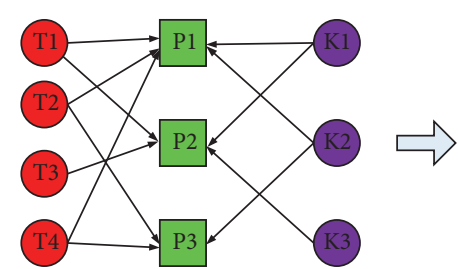

(f)

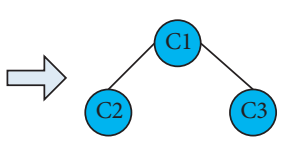

(c)

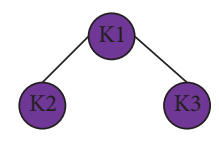

(g)

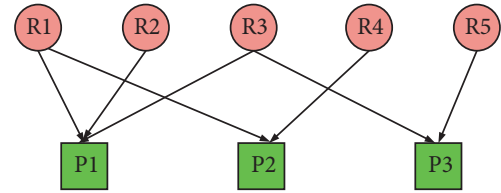

(d)

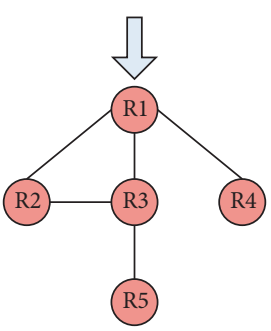

(h)

Figure 1: Pictorial view of network construction. Note: A is the abbreviation of author, $\mathrm{C}$ is country, $\mathrm{P}$ is paper, $\mathrm{R}$ is reference, T is term, and $\mathrm{K}$ is keyword. The thickness of a line denotes the weight of the edge. The color of a circle represents the node type. (a) Authorcollaboration network. (b) Author-article-country relationship. (c) Country-collaboration network. (d) Reference-article relationship. (e) Terms co-occurrence network. (f) Terms-article-keywords relationship. (g) K.eywords cooccurrence network. (h) Cocitation network.

Sliding window analysis identifies the evolution of cocitation network and demonstrates structural changes in the research trend over time. Field knowledge is updated year by year and consequently the associated network evolves over time. To investigate the emerging trends, we divide the article series from 2000 to 2020 into fragments with a length of 5 years (the size of the sliding windows could neither be too small nor too large. If too small, there will be a limited number of references and in turn the chosen nodes, in the constructed network, which makes the clustering meaningless. For example, if the size of sliding windows is 2 (year), there are only 8 nodes in the 2000 2001 network. On the other hand, if the size is too large, the constructed networks become difficult to capture the detailed information of structural changes. After balancing information loss and statistical significance, the size is chosen to be 5 (year) and the starting year is 2000 so that every constructed network consists of at least 30 nodes) through sliding windows with a sliding step of 1 year (see Figure 2), and each fragment is used to construct a network. The reason to adopt the sliding windows approach is to fully use the feature of memory and transitivity contained in fragments [36]. After the sliding window process, we obtain a series of 17 networks from which we can learn the change of modularity and thus analyze the evolution features.

\subsection{Network Indicators and Scientometric Metrics.} Betweenness centrality, clustering-related indicators, modularity, silhouette, and burst-related indicators are the main metrics for visualizing and analyzing.

The betweenness centrality of node $i, \mathrm{bc}(i)$, is defined as the following equation:

$$
\mathrm{bc}(i)=\sum_{s \neq i \neq t} \frac{p_{\mathrm{st}}^{i}}{p_{\mathrm{st}}},
$$

where $p_{\text {st }}$ is the number of the shortest paths between nodes $s$ and $t$ and $p_{\mathrm{st}}^{i}$ is the number of these shortest paths that pass through node $i$. High betweenness centrality emphasizes the importance of nodes in connecting different clusters and identifies potentially revolutionary scientific publications.

Clustering: cocitation similarities $(\sigma)$ between articles $i$ and $j$ are calculated through cosine coefficients. Let $A$ be the set of articles that cites $i$ and $B$ the set of papers that cites $j$; then the similarity can be defined as the following equation:

$$
\sigma_{\mathrm{ij}}=\frac{|A \cap B|}{\sqrt{|A| \cup|B|}},
$$

where $|A \cap B|$ is the cocitation counts, $|A|$ is the citation counts of $i$, and $|B|$ is the citation counts of $j$. Define a cluster of a network $G$ as one subgraph $G_{k}$ such that $G=\cup_{k=1} G_{k}$ and $G_{m} \cap G_{n}=\varnothing$ for all $m \neq n$, and a cut function $f$ as the following equation (see more in Shi and Malik [37]):

$$
f\left(G_{m}, G_{n}\right)=\sum_{i \in G_{m}, j \in G_{n}} \sigma_{i j}
$$

The goal of clustering is to maximize $\sum_{k=1} f\left(G_{k}, G_{k}\right)$ and minimize $\sum_{k=1} f\left(G_{k}, G-G_{k}\right)$, and spectral clustering is an efficient approach to that end [38]. In CiteSpace, clusters are automatically generated based on the abovementioned ideas.

To better visualize the clusters, CiteSpace labels generated clusters by ranking algorithms such as TF* IDF, loglikelihood ratio (LLR) tests, or mutual information. LLR algorithm is adopted here to select the labels for corresponding clusters. The rationale behind this choice is that the terms selected by LLR highlight the unique aspect of a cluster, and LLR is good at generating high intraclass similarity and low interclass similarity [38]. The other clustering-related visualization tool is timeline mapping, which is a global visualization of the network. Cluster labels are shown vertically at the right-hand side, and the publication years of the articles are shown in an upper horizontal timeline. Timeline mapping is a helpful tool in obtaining the 


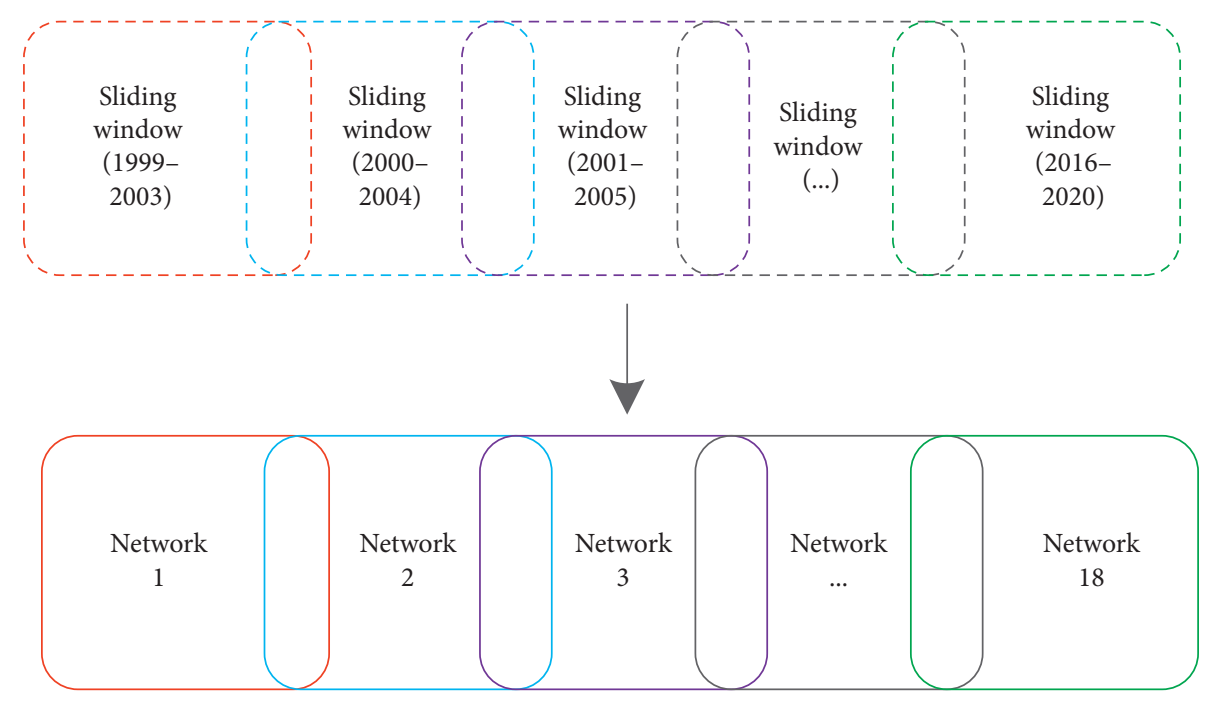

FIgURE 2: Sliding window process.

timespan, evolution process of one cluster, and the influential articles along the evolution process.

Modularity $Q$ and silhouette are two metrics used for assessing the cluster-related features in a network. Assume a network can be divided into $c$ communities, then $Q$ can be calculated from a symmetric $c \times c$ matrix whose elements, along the main diagonal, $q_{m m}$ denote the fraction of edges connecting nodes in the same community $m$ while the other elements $q_{m n}(m \neq n)$ represent the fraction of edges linking nodes in the different communities $m$ and $n$, according to [39], and $Q$ is defined by the following equation:

$$
Q=\sum_{m}\left[q_{m m}-\left(\sum_{n} q_{m n}\right)^{2}\right] .
$$

The modularity measures the extent to which a network can be divided into independent clusters and is a global measure of the overall structure of the network, and its score ranges from 0 to 1 . The larger $Q$ is, the more well-structured a network is. Since modularity is defined for any network, one may use modularity values to compare different networks [38]. Q>0.3, a usual empirical threshold of significance, means that the detected community structure is significant. As argued by Chen et al. [40], the intellectual structure of a scientific field can be analyzed by the modularity of the associated cocitation network, which evolves over time, and newly published articles may introduce a profound structural variation on the network.

Silhouette is proposed by Rousseeuw [41], measuring the quality of a clustering configuration, and suggests the uncertainty that one needs to consider when interpreting the nature of the cluster. Let $D$ be the cluster in which node $i$ is present and $C$ is any cluster which is different from $D, a(i)$ is the average length of all edges within $D$, and $b(i)$ is the minimum of the average length of all edges going from $i$ to $C$; then define $S$ as the following equation:

$$
S(i)=\frac{b(i)-a(i)}{\max \{a(i), b(i)\}}
$$

The value of $S$ ranges between -1 and 1, with 1 representing a perfect separation from other clusters. Empirically, the result is persuasive if the silhouette value is $0.7-0.9$ and it is reasonable if the score is above 0.5 .

Citation burstiness analysis detects potential articles that drive emerging research interests. The burstiness of the frequency of an article over time indicates a specific duration in which an abrupt change of the frequency takes place [29] and is developed to find a set of fast-rising terms used by scholars in their latest publications. Kleinberg [42] developed an algorithm to calculate and detect abrupt changes and its idea later was introduced into the software CiteSpace by [43]; see equations (7)-(9). Assume the citation growth model is expressed as the following equation:

$$
F(t)=\mathrm{ae}^{\mathrm{bt}},
$$

where $a$ is the initial citation times (i.e., $F(0)), b$ is the annual growth rate of citation, and $t$ is time. Therefore, the 2-time citation growth (one parameter setting in CiteSpace) can be expressed as the following equation:

$$
\frac{F\left(t_{2}\right)}{F\left(t_{1}\right)}=e^{b\left(t_{2}-t_{1}\right)}=2 .
$$

Take log transformation on both sides of the right-hand of equation (8); we obtain

$$
d=t_{2}-t_{1}=\frac{\ln 2}{b} .
$$

There are two attributes for a citation burstiness, that is, the intensity of burst $(b)$ and burst duration (the number of years that citation grows at $b$ ) [40]. Different term/article has different burstiness.

2.3. Data Collection and Parameters Setting in CiteSpace. There are several primary databases that can be adopted in the process of scientometric analysis, like Web of Science 
(WoS), Scopus, and Google Scholar. With a comparative assessment of these databases, Olawumi and Chan [44] have pointed out that WoS covers various core journals' publishing houses and most relevant journals in its records. In this sense, we select the core collections of the WoS as the data source to include only high-quality SCI/SSCI publications. 114 records published from 1995 to 2020 are collected initially. However, the 114 records do not include relevant publications if the terms "digital currency," "electronic payment," and "digital money" do not explicitly appear in the titles, abstracts, or index terms. Therefore, in the second step, we expand the dataset with a citation indexing method following Chen et al. [40]. The assumption of the approach is intuitive; that is, citing at least one of the 114 records makes the citing article relevant to the topic. According to Chen et al. [40], the citation index-based expansion has the advantage of obtaining a self-contained dataset. Finally, a total of 454 records were obtained after data merging and deduplication.

In this review, CiteSpace (version 5.6.R5) is used as a knowledge management tool to get an in-depth understanding of the intellectual structure and emerging frontiers of the concerned research area. The software gradually develops along the path of scientometric, citation analysis, cocitation analysis, and cocitation visualization; is outstanding in clustering literature, visualizing the intellectual structure; and is specifically designed to facilitate the detection of emerging trends and abrupt changes in scientific literature $[24,45]$.

The basic parameters include a time interval from 1995 to 2020 , time slice $=1$ year, term source $=$ title $/$ abstract $/$ author, key words/key words plus. Time slicing is a dividing strategy, and time slicing by one year means dividing the whole period of 1995-2020 into 26 subperiods, resulting in 26 networks. Setting a small number for time slicing can reveal the evolution trend and its features. Top $\mathrm{N}$ per slice is a parameter setting to select nodes to be shown in the corresponding networks. In this study, we set $N=100$ to choose the most relevant and critical data, which means that only the top-cited 100 records are shown in each network. Besides, we choose the pruning algorithm of "pathfinder within the merged network" to simplify the resulting 26 cocitation networks and emphasize the key structure. Figure 3 illustrates the basic framework of the running CiteSpace.

\section{The Intellectual Network of DC/EP}

After running CiteSpace, we conduct a cluster analysis of the cocitation network to show the knowledge bases and intellectual structure of DC/EP from a perspective of spatial distribution as well as a chronological evolutionary path.

3.1. Summary Description. CiteSpace divides the cocitation network into several clusters of cocited references such that references are tightly connected within the same clusters, but loosely connected between different clusters. The overview clusters mapping of cited references in our dataset are shown in Figure 4, where cluster labels are in red, and node labels are in black with font size proportional to citation counts. The modularity $(Q)$ of the network is 0.82 , which is higher than the threshold level of 0.3 , indicating that the clustering is significant.

Table 1 lists the largest eight clusters of cited references, marked out by different colors in Figure 4, which are ranked by their sizes. Cluster \#1 is the biggest one with 60 articles. All clusters in Table 1 are highly homogeneous, since their silhouette values are all larger than 0.9 , implying that the reference cluster of this study is effective and meaningful. The average year of publication of a cluster indicates its recentness. Cluster $\# 2$ is the most recently formed cluster with an average year of 2018 .

Figure 5 shows a timeline visualization of the cocitation clusters to illustrate the chronological dynamics of each cluster. For example, the evolutionary path of the largest cluster, Cluster \#1, is exhibited in the first line. It could be seen that the forming year of this cluster is 2010 , with a rising number of in-cluster references around 2013. The most cited reference in this cluster was published in 2016 by Dyhrberg [46], marked as the biggest yellow node along the timeline, and the article with the high betweenness centrality in this cluster appeared in 2015 [47], surrounded with a thick purple ring in the timeline.

3.2. Knowledge Bases. Knowledge base analysis provides a foundation for future DC/EP research. Two types of key references in the cocitation network can be seen as forming the knowledge bases of the research field: (1) landmark nodes with high citation frequency, suggesting their intracluster importance, and (2) boundary spanner nodes with high betweenness centrality, indicating their intercluster importance.

Table 2 lists the top eleven cited articles. Both Cluster \#1 and Cluster \#9 have 4 articles in the top landmarks. The remaining three are all from Cluster \#5. The most cited article in our dataset is Dyhrberg [46] with 116 citations, followed by Cheah and Fry [48] and Dwyer [49], both with 101 citations. These three top-cited articles are all from Cluster \#1, which will be discussed in more detail in the following Subsection 3.3.

Urquhart [50] from Cluster \#9, which ranks the fourth, pioneered in studying the market efficiency of Bitcoin. The work is followed by another two highly cited articles from the same cluster, Nadarajah and Chu [51] and Bariviera [52]. All of them concluded that the market of Bitcoin is inefficient or only efficient in specific periods. Besides, Bariviera [52] further showed that price volatility, measured as the logarithmic difference between intraday high and low prices, exhibits long memory during all the period, which reflects a different underlying dynamic process generating the prices and volatility. This is echoed by Katsiampa [53], also with a high citation in Cluster \#9, which explored the optimal conditional heteroskedasticity model with regard to goodness-of-fit to Bitcoin price data and found that the AR-CGARCH 


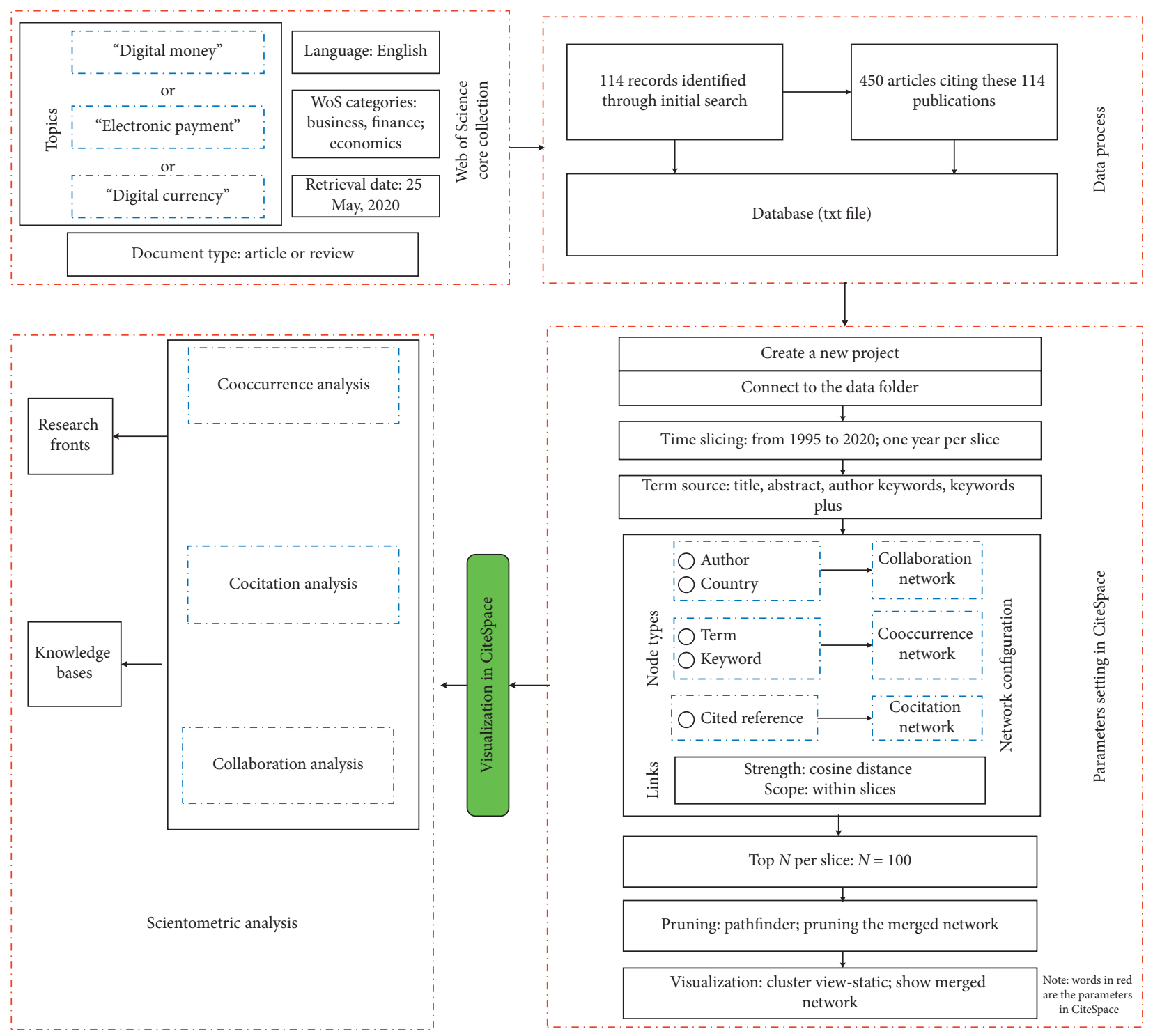

Figure 3: Framework of this study.

model, including both a short-run and a long-run component of the conditional variance, is the best.

The fifth and sixth ranking papers are both from Cluster \#5, broadly focusing on the usage of private digital currencies. Specifically, Baur et al. [54] analyzed the statistical properties of Bitcoin to study the prevailing usage of private digital currencies and found that they are mainly used as a speculative investment rather than an alternative currency and medium of exchange, whereas Bouri et al. [11] used a dynamic conditional correlation model to examine whether Bitcoin can act as a hedge and safe haven for major world stock indices, bonds, oil, gold, the general commodity index, and the US dollar index. Interestingly, their work indicates that Bitcoin is a poor hedge and is suitable as a safe haven against weekly extreme down movements in Asian stocks only.

Table 3 shows seven structurally essential references, with the highest betweenness centrality values, in the synthesized network. These references are important in terms of not only how they connect individual nodes in the network but also how they connect aggregated groups of nodes. Two of these nodes are in Cluster \#2 and two in Cluster \#1. These works can be seen as bridge works in promoting paradigm shift or theme-switching of DC/EP research.

Platanakis and Urquhart [55] from Cluster \#2 are with the highest betweenness value and analyze the potential out-of-sample portfolio benefits resulting from including Bitcoin in a stock-bond portfolio for a range of eight popular asset allocation strategies. Selgin [47] from Cluster \#1 ranks the second, which casts fundamental insights into the monetary system. It argues that a properly designed synthetic commodity money may supply the foundation for a monetary regime, and this regime does not require oversight by any monetary authority, yet it is able to generate a stable macroeconomy. 


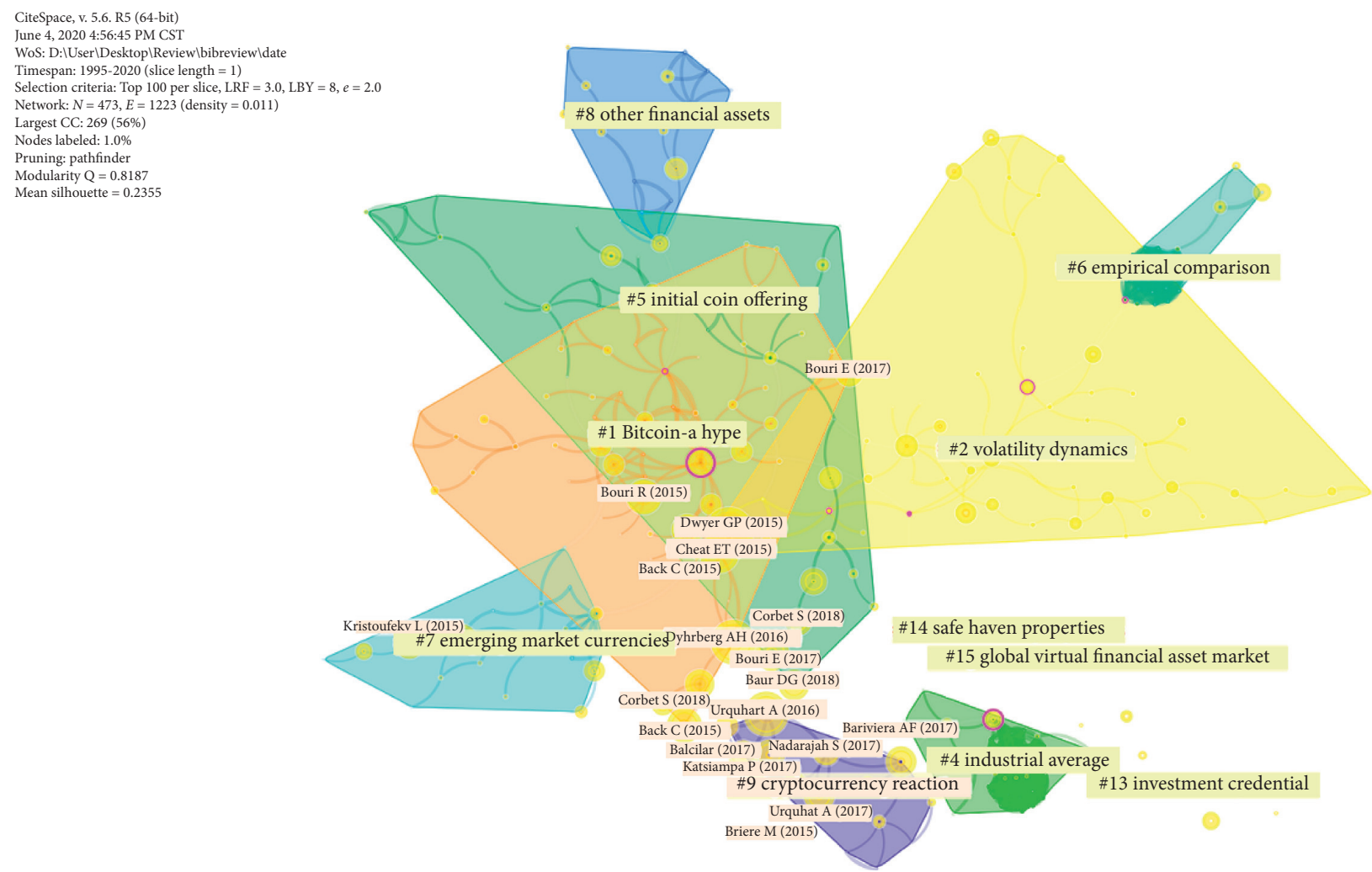

Figure 4: Clusters of cited references on DC/EP (1995-2020). Clusters are in different colors, and their labels are in red text. Landmark articles are labeled in black with font size proportional to citation counts.

TABLE 1: Major clusters of cited references on DC/EP (1995-2020).

\begin{tabular}{lcccc}
\hline Cluster \# & Size & Silhouette & Label (LLR) & Year ave. \\
\hline 1 & 60 & 0.945 & Bitcoin-a hype & 2015 \\
2 & 54 & 0.918 & Volatility dynamics & 2018 \\
4 & 36 & 0.971 & Industrial average & 2014 \\
5 & 31 & 0.959 & Initial coin offering & 2017 \\
6 & 25 & 0.998 & Empirical comparison & 2016 \\
7 & 20 & 0.981 & Emerging market currencies & 2013 \\
8 & 16 & 0.997 & Other financial assets & 2015 \\
9 & 14 & 0.964 & Cryptocurrency reaction & 2017 \\
\hline
\end{tabular}

Alvarez-Ramirez et al. [56] from Cluster \#4 rank the third and study long-range correlations and informational efficiency of the Bitcoin market.

3.3. Review of Major Clusters. Tables 4 and 5 list five critical citing papers and five key cited publications in the major Clusters \#1 and \#2, respectively.

The core members of Cluster \#1 represent major milestones in DC/EP, notably Dyhrberg [46] with the highest citations. Using an asymmetric GARCH model, Dyhrberg [46] explored the hedging capability of Bitcoin and found that Bitcoin can be used as a hedge against both stocks in the Financial Times Stock Exchange Index and American dollar in the short term. The second most cited references are Cheah and Fry [48], which discovered speculative bubbles in the Bitcoin market through econometric modeling of Bitcoin prices, and Dwyer [49] theoretically explained how applied financial technologies and limitation of the quantity produced can create an equilibrium in which a digital currency has a positive value. Ciaian et al. [57] incorporated specific factors of digital currencies in studying the price formation process and thus obtained a high citation.

More recent works with significance in DC/EP are contained in Cluster \#2. Phillip et al. [58] top the other in citations in Cluster \#2. They integrated stylized attributes in a single model to measure the varied nature and price dynamics of 224 different cryptocurrencies and demonstrated that most of them have leverage effects and Student's $t$ error distributions. The other most cited reference is Kim [59], which examined transaction costs of Bitcoin in international transactions using Bitcoin quotes data in 16 different currencies and found that the transaction cost of Bitcoin is lower than that of the retail foreign exchange rate.

Among the five major citing articles related to Clusters \#1 and \#2, four articles are similar, namely, Bedi and Nashier [60], Ahmed [61], Charfeddine et al. [62], and Klarin [63], which are all published in 2020. Their high coverage of references in both clusters suggests significant relevance to the field of DC/EP. Bedi and Nashier [60] have the highest citation coverage in both Clusters \#1 and \#2. Adopting a similar method to that of Dyhrberg [46] that used modified conditional VAR as a measurement of risk, Bedi and Nashier [60] examined the diversification capability of Bitcoin. Different from Dyhrberg [46], they only focused on various fiat currency assets and 

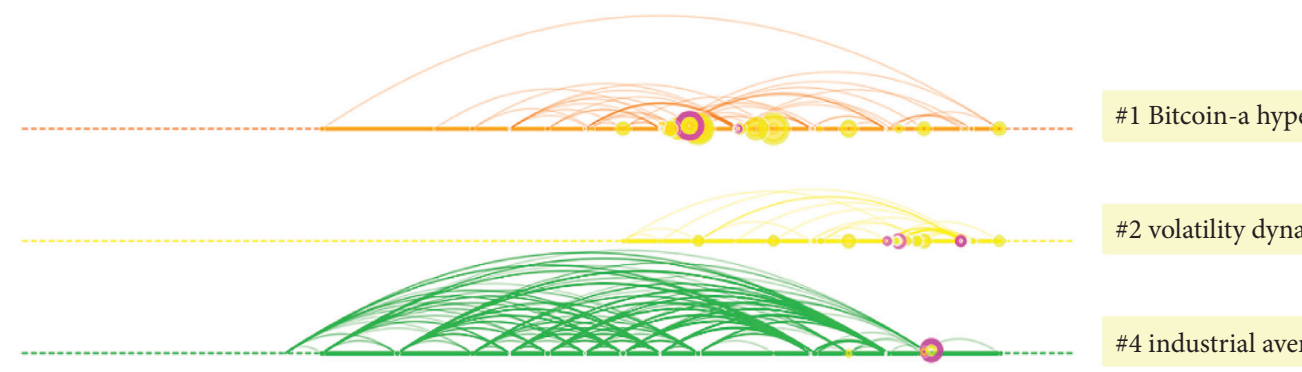
\#2 volatility dynamics

\#4 industrial average

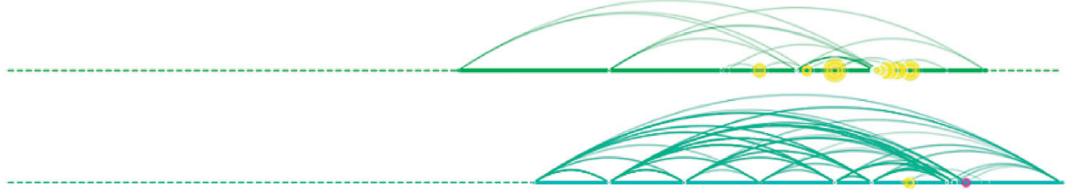

\#5 initial coin offering

\#6 empirical comparison

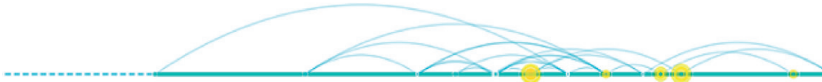

\#7 emerging market currencies

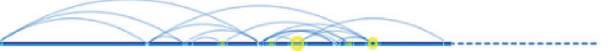

\#8 other financial assets

\#9 cryptocurrency reaction

Figure 5: Timelines of cocitation clusters. Major clusters are labeled on the right with different colors. Yellow circles on the horizontal lines represent high citation articles and purple circles denote high betweenness nodes.

performed comprehensive risk-adjusted portfolio evaluations across three asset allocation strategies, providing insights into the sharp disparity in Bitcoin trading volumes across national currencies from a portfolio theory perspective. The other citing articles also focus on the price dynamics and economic role of Bitcoin in asset allocation, with modifications to either asset classes, data frequency, or risk measurement methods.

\section{Emerging Trends of DC/EP}

In this section, we detect emerging trends of $\mathrm{DC} / \mathrm{EP}$ research with CiteSpace from two perspectives: (1) cocitation analysis in terms of references and (2) cooccurrence analysis in terms of keywords and terms.

\subsection{Detecting Emerging Trends from Cocitation Network.} Emerging trends in the DC/EP research from cocitation network are detected by combining sliding window analysis and burst detection. The collective intellectual structure of the cocitation network in a specific area evolves over time. Newly published articles may introduce profound structural variation, which temporally reduce the modularity of the cocitation network $[40,64]$ and lead to emerging trends in the research field. To detect these emerging trends, the dynamics of modularity is investigated by sliding window analysis. Figure 6 shows the dynamics of the modularity of the 17 constructed cocitation networks. It could be seen that the local minimum of modularity appeared in 2003, 2010, and 2013, which suggests that structural variations occurred, or some new research trends emerged, around these years.
To detect what these trends are and which publications play important roles in forming them, we analyze the citation burst of publications in the whole dataset. If a publication has a citation burst starting from 2003, 2010, or 2013, it is likely to introduce a structural change to the cocitation network and lead to a new research trend. Figure 7 lists the publications whose beginning citation burst years are 2003, 2010, or 2013.

The publications with citation burst year beginning in 2003 mainly studied the factors that affect buyers' trust in sellers and their intention to purchase goods on the electronic markets. For example, Doney and Cannon [65] examined, both theoretically and empirically, the cognitive processes through which buyers develop trust of a seller. Gefen [66] tested the hypothesis that familiarity and trust influence buyers' intention to purchase online goods using survey data from 217 potential e-commerce users and found that people's disposition to trust is the primary factor that affects their trust in the vendor. Based on economic theories and data from online experiments, $\mathrm{Ba}$ and Pavlou [67] examined the extent to which trust can be induced by a proper feedback mechanism in the electronic markets and how risk factors affect trust formation. They demonstrated that appropriate feedback mechanisms can induce calculusbased credibility trust without repeated interactions between two transacting parties. Trust can mitigate information asymmetry by reducing transaction-specific risks, thus generating price premiums for reputable sellers. It could be inferred from these cited references that rising interest in buyer's choice behavior of an electronic transaction in the 
TABLE 2: Most cited references.

\begin{tabular}{lcc}
\hline Citation counts & References & Cluster \# \\
\hline 116 & Dyhrberg, 2016, FINANC RES LETT, V16, P85 & 1 \\
101 & Cheah and Fry, 2015, ECON LETT, V130, P32 & 1 \\
101 & Dwyer, 2015, J FINANC STABIL, V17, P81 & 1 \\
94 & Urquhart, 2016, ECON LETT, V148, P80 & 9 \\
86 & Baur et al., 2018, FINAN RES LETT, V0, P0 & 5 \\
79 & Bouri et al., 2017, FINANC RES LETT, V20, P192 & 5 \\
65 & Nadarajah and Chu, 2017, ECON LETT, V150, P6 & 9 \\
62 & Katsiampa, 2017, ECON LETT, V158, P3, & 9 \\
61 & Ciaian et al., 2016, APPL ECON, V48, P1799 & 1 \\
58 & Bariviera, 2017, ECON LETT, V161, P1 & 9 \\
\hline
\end{tabular}

Table 3: Cited references with the highest betweenness centrality.

\begin{tabular}{lccc}
\hline Rank & Centrality & References & Cluster \# \\
\hline 1 & 0.39 & Platanakis and Urquhart, 2019, BRIT ACCOUNT REV, V0, P0 & 2 \\
2 & 0.33 & Selgin, 2015, J FINANC STABIL, V17, P92 & 1 \\
3 & 0.23 & Alvarez-Ramirez et al., 2018, PHYSICA A, V492, P948 & 4 \\
4 & 0.17 & Dyhrberg, 2018, ECON LETT, V171, P140 & 2 \\
5 & 0.10 & Hendrickson, 2016, ECON INQ, V54, P925 & 1 \\
6 & 0.10 & Urquhart, 2019, INT REV FINANC ANAL, V63, P49 & 6 \\
7 & 0.10 & Feng, 2018, FINANC RES LETT, V26, P63 & 5 \\
\hline
\end{tabular}

Table 4: Citing articles and cited references of Cluster \#1.

\begin{tabular}{|c|c|c|c|}
\hline \multicolumn{4}{|c|}{ Cluster \#1 Bitcoin-a hype } \\
\hline & Citing articles & & Cited references \\
\hline Coverage $\%$ & Author (year): title & Cites & $\begin{array}{l}\text { Author (year), journal, } \\
\text { volume, page }\end{array}$ \\
\hline 49 & $\begin{array}{l}\text { Bedi and Nashier (2020): On the Investment } \\
\text { Credentials of Bitcoin: A Cross-Currency Perspective }\end{array}$ & 116 & Dyhrberg (2016), FINANC \\
\hline 32 & $\begin{array}{l}\text { Ahmed (2020): Is There a Risk-Return Trade-Off in } \\
\text { Cryptocurrency Markets? The Case of Bitcoin }\end{array}$ & 101 & $\begin{array}{l}\text { Cheah and Fry (2015), } \\
\text { ECON LETT, V130, P32 }\end{array}$ \\
\hline 25 & $\begin{array}{l}\text { Charfeddine et al. (2020): Investigating } \\
\text { the Dynamic Relationship between Cryptocurrencies and } \\
\text { Conventional Assets: Implications for Financial Investors }\end{array}$ & 101 & $\begin{array}{l}\text { Dwyer (2015), J FINANC } \\
\text { STABIL, V17, P81 }\end{array}$ \\
\hline 24 & $\begin{array}{l}\text { Saiedi (2020): Global Drivers of Cryptocurrency } \\
\text { Infrastructure Adoption }\end{array}$ & 61 & $\begin{array}{l}\text { Ciaian et al. (2016), } \\
\text { APPL ECON, V48, P1799 }\end{array}$ \\
\hline 22 & $\begin{array}{l}\text { Klarin (2020): The Decade-Long Cryptocurrencies and the Blockchain } \\
\text { Rollercoaster: } \\
\text { Mapping the Intellectual Structure and Charting Future Directions }\end{array}$ & 53 & $\begin{array}{l}\text { Bohme et al. (2015), J ECON PERSPECT, V29, } \\
\text { P213 }\end{array}$ \\
\hline
\end{tabular}

research of DC/EP might start from 2003. This trend may be related to the gradual development of e-commerce after the Internet technology booming.

As to the publications with citation burst year beginning in 2010, Schuh and Stavins [68] studied the determinants of the use of different payment instruments. They demonstrated that the changes in relative convenience and cost as well as the changes in relative characteristics of substitute payment instruments contribute to the corresponding choice. Bolt et al. [12] empirically analyzed the impact of surcharging on the demand for debit card based on consumer and retailer survey data in the Netherlands and found that surcharging steers consumers away from using debit cards towards cash services. Zinman [69] tested the neoclassical consumer choice model, concerning debit card use versus credit card use, in the presence of behavioral considerations, such as self-control issues, complex intertemporal trade-offs, and low pecuniary stakes, and concluded that the neoclassical model adequately explains consumer choice even on a margin where behavioral alternatives have strong intuitive appeal. In summary, these references suggest a rising trend in DC/EP research that focuses on the determinants of consumer's choice of different payment instruments.

Further, for the publications with citation burst year beginning in 2013, Ching and Hayashi [70] and CarboValverde and Linares-Zegarra [71] studied the effectiveness of rewards card programs on consumer payment choice with respect to debit/credit cards and cash and suggested that rewards may significantly modify preferences for payment 
TABLE 5: Citing articles and cited references of Cluster \#2.

\begin{tabular}{|c|c|c|c|}
\hline \multicolumn{4}{|c|}{ Cluster \#2 volatility dynamics } \\
\hline \multicolumn{2}{|r|}{ Citing articles } & \multicolumn{2}{|r|}{ Cited references } \\
\hline $\begin{array}{l}\text { Coverage } \\
\%\end{array}$ & Author (year): title & Cites & Author (year), journal, volume, page \\
\hline 36 & $\begin{array}{c}\text { Bedi and Nashier (2020): On the Investment Credentials of Bitcoin: A Cross- } \\
\text { Currency Perspective }\end{array}$ & 31 & $\begin{array}{c}\text { Phillip et al. (2018), ECON LETT, V163, } \\
\text { P6 }\end{array}$ \\
\hline 25 & $\begin{array}{c}\text { Ahmed (2020): Is There a Risk-Return Trade-Off in Cryptocurrency } \\
\text { Markets? The Case of Bitcoin }\end{array}$ & 31 & $\begin{array}{l}\text { Kim (2017), FINANC RES LETT, V23, } \\
\text { P300 }\end{array}$ \\
\hline 20 & $\begin{array}{l}\text { Dong and Hao (2020): The Asymmetric Effect of Volatility Spillover in } \\
\text { Global Virtual Financial Asset Markets: The Case of Bitcoin }\end{array}$ & 27 & $\begin{array}{l}\text { Raskin and Yermack (2015), HDB } \\
\text { DIGITAL CURRENCY, V0, P31 }\end{array}$ \\
\hline 20 & $\begin{array}{c}\text { Charfeddine et al. (2020): Investigating the Dynamic Relationship between } \\
\text { Cryptocurrencies and Conventional Assets: Implications for Financial } \\
\text { Investors }\end{array}$ & 26 & $\begin{array}{c}\text { Gandal (2018), J MONETARY ECON, } \\
\text { V95, P86 }\end{array}$ \\
\hline 17 & $\begin{array}{l}\text { Klarin (2020): The Decade-Long Cryptocurrencies and the Blockchain } \\
\text { Rollercoaster: Mapping the Intellectual Structure and Charting Future } \\
\text { Directions }\end{array}$ & 25 & $\begin{array}{l}\text { Vidal-Tomas (2018), FINANC RES } \\
\text { LETT, V27, P259 }\end{array}$ \\
\hline
\end{tabular}

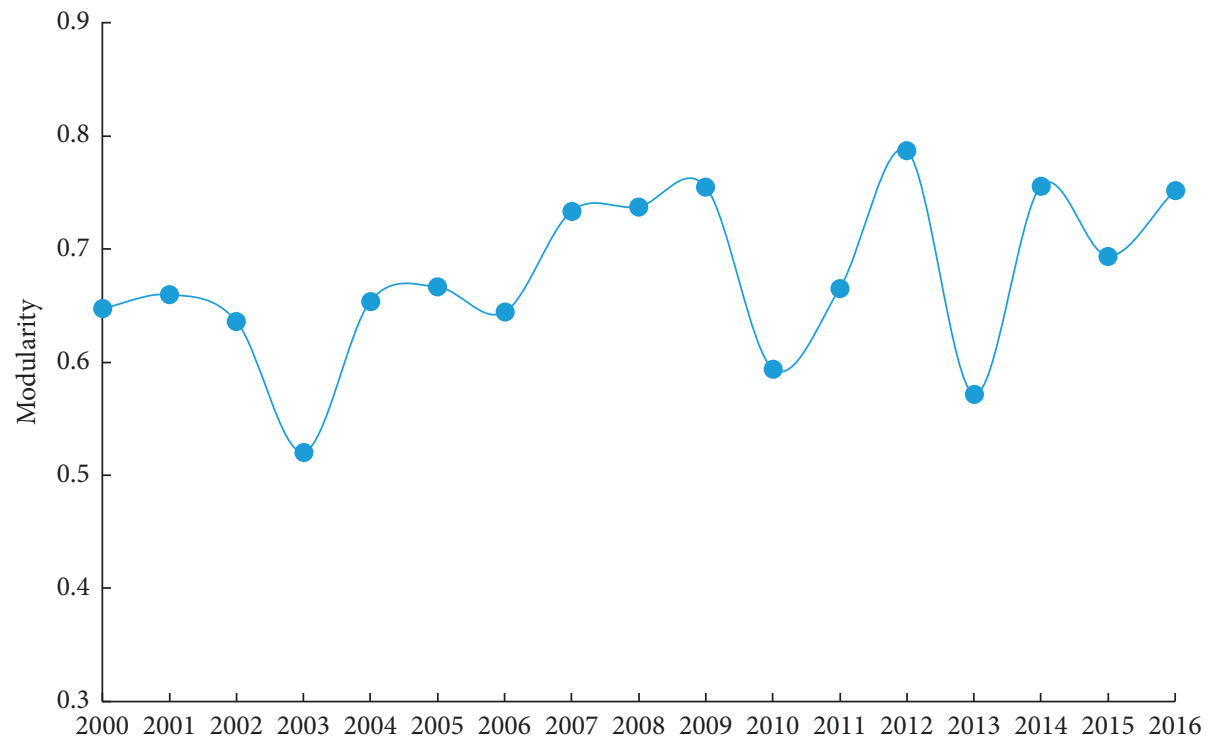

Figure 6: The dynamics of modularity from 2000 to 2020, that is, 17 cocitation networks constructed from sliding windows with a size of 5 (year) and step length of 1 (year).

instruments and their economic impacts vary significantly across types of rewards and merchant activities. Klee [72] studied the relationship between money demand and consumer payment behavior based on empirical evidence from grocery store transaction data and showed that there are statistically significant effects of transaction costs, opportunity costs, and product characteristics on the choice of payment instrument, which, in turn, affect money demand. He et al. [73] emphasized the ignorance of the payment system and bank's role in the provision of convenient, efficient, and safe instruments by mainstream banking theory and introduced a risk of theft, including fraud, embezzlement, counterfeiting, and many other kinds of opportunistic behavior, and a safe-keeping role for banks into modern monetary theory. The general equilibrium model can generate the concurrent circulation of cash and bank liabilities as media of exchange, or inside and outside money, as well as yield novel policy implications, such that negative nominal interest rates are feasible and for some parameters optimal. These articles probably indicate an emerging trend that reflects on how consumer's choice of payment instruments affects money demand and in turn influences the bank's role and their policy implications.

4.2. Detecting Emerging Trends from Keywords Network. The above subsection analyzes the emerging trends of research in DC/EP from the perspective of cocitation network. In this subsection, we use CiteSpace to conduct a network analysis concerning the terms and keywords occurring in the dataset. Twelve clusters are formed with modularity of 0.77 . Table 6 lists the top four clusters in terms of their recentness, whereas Table 7 shows five keywords in each of these clusters with the highest frequency. The keywords followed by "* " are with citation bursts, notably "digital currency" and "money" (see Figure 8). 


\begin{tabular}{|c|c|c|c|c|}
\hline References & Strength & Begin & End & $1995-2020$ \\
\hline Lee MKO., 2001, INT J ELECTRON COMM, V6, P75 & 5.6219 & 2003 & 2008 & \\
\hline Hoffman DL., 1999, COMMUN ACM, V42, P80 & 8.3864 & 2003 & 2007 & عسمس \\
\hline Jarvenpaa S L., 2000, ITM, V1, P45 & 7.7384 & 2003 & 2007 & 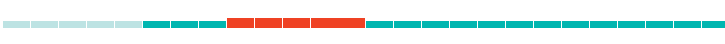 \\
\hline Ba SL., 2002, MIS QUART, V26, P243 & 4.9954 & 2003 & 2008 & نصسمس \\
\hline Doney PM., 1997, J MARKETING, V61, P35 & 3.9959 & 2003 & 2005 & - inس \\
\hline Gefen D., 2000, OMEGA-INT J MANAGE S, V28, P725 & 4.5058 & 2003 & 2007 & 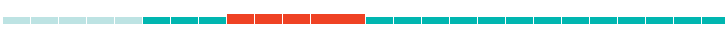 \\
\hline McKnight DH., 2001, INT J ELECTRON COMM, V6, P35 & 10.6506 & 2003 & 2008 & تصسمساست \\
\hline Borzekowski R., 2008, J MONEY CREDIT BANK, V40, P149 & 11.7265 & 2010 & 2016 & 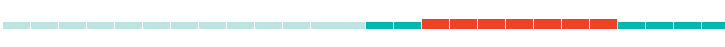 \\
\hline Jonker N., 2007, ECONOMIST-NETHERLAND, V155, P271 & 9.2111 & 2010 & 2015 & r-m \\
\hline Schuh S., 2010, J BANK FINANC, V34, P1745 & 9.6846 & 2010 & 2017 & \\
\hline Zinman J., 2009, J BANK FINANC, V33, P358 & 5.2929 & 2010 & 2013 & 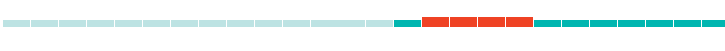 \\
\hline Bolt W., 2010, J BANK FINANC, V34, P1738 & 6.1718 & 2010 & 2017 & r|س \\
\hline Ching AT., 2010, J BANK FINANC, V34, P1773 & 7.6843 & 2013 & 2017 & - \\
\hline Klee E., 2008, J MONETARY ECON, V55, P526 & 5.7397 & 2013 & 2016 & - \\
\hline Carbo-Valverde S., 2011, J BANK FINANC, V35, P3275 & 4.8293 & 2013 & 2017 & 年 \\
\hline He P., 2008, J MONETARY ECON, V55, P1013 & 3.8222 & 2013 & 2016 & ماسف \\
\hline Borzekowski R., 2008, INT J IND ORGAN, V26, P889 & 3.8222 & 2013 & 2016 & | \\
\hline
\end{tabular}

FIgURE 7: The publications with citation burst year beginning in 2003, 2010, or 2013.

TABLE 6: Most recently formed clusters of keywords.

\begin{tabular}{lcccc}
\hline Cluster \# & Size & Silhouette & Ave. year & Label (LLR) \\
\hline 10 & 13 & 0.913 & 2019 & Confirmatory bias \\
11 & 12 & 0.958 & 2019 & Price discovery \\
1 & 23 & 0.902 & 2018 & Yellow metal \\
5 & 16 & 0.947 & 2018 & Central bank \\
\hline
\end{tabular}

Cluster \#10 is mainly related to behavioral finance and focuses on how social media and investor sentiment affects cryptocurrency markets $[74,75]$. Cluster \#11 focuses on the price discovery determinants and volatility dynamics of digital currencies $[76,77]$. Cluster \#1 is a larger one on the topic of hedge, diversification effect of digital currencies, and their comparison with gold [78, 79].

The topic of Cluster \#5 is the most distinct one that concentrates on the impact of digital currency on the central bank, monetary policy, and central bank digital currency (CBDC). For example, following an analysis of private digital currencies, Dow [80] considered proposals for the state issue of digital currency and concluded that regulation updating should be a main focus. Bindseil [81] made a further discussion on the pros and cons of CBDC. To cope with the potential drawbacks, they proposed a twotier remuneration of CBDC as a solution and a tested and simple tool to control the quantity of CBDC in both normal and crisis times. Also, Hampl and Havranek [82] examined the use of central bank equity as an unconventional monetary policy tool and argued that it may weaken the financial strength of the central bank and endangers longterm price stability.
TABLE 7: Top five keywords in each recent cluster.

\begin{tabular}{lcc}
\hline & Freq. & Keyword \\
\hline & 29 & Price \\
Cluster \#10 & 18 & Portfolio diversification \\
& 9 & Sentiment \\
& 5 & Social media \\
& 5 & Performance \\
\hline Cluster \#11 & 27 & Digital currency \\
& 23 & Exchange \\
& 18 & Stock \\
& 10 & Price discovery \\
& 9 & Bubble \\
\hline & 51 & Gold \\
Cluster \#1 & 23 & Dollar \\
& 18 & Currency \\
& 10 & Time series \\
& 9 & Long memory \\
\hline & 18 & Money* \\
Cluster \#5 & 10 & Garch \\
& 7 & Monetary policy \\
& 5 & Volatilityspillover \\
& 4 & Connectedness \\
\hline
\end{tabular}

Note: the keywords followed by “*” are with citation bursts.

\section{Collaboration Network of DC/EP}

In this section, we analyze the international academic collaboration network and demonstrate the main distribution of DC/EP research in the networks of authors and countries.

5.1. Core Scholars and Collaboration Network. The authors with high citations can be viewed as core scholars. Table 8 summarizes the top ten cited authors and reflects their 
TABLE 8: Most cited authors.

\begin{tabular}{lccc}
\hline Author & Citing counts & Cluster \# & Label (LLR) \\
\hline Dyhrberg & 120 & 3 & Hedging effectiveness \\
Baur et al. & 118 & 7 & Energy commodities \\
Bouri et al. & 117 & 10 & Investor reaction \\
Urquhart & 115 & 3 & Hedging effectiveness \\
Cheah and Fry & 108 & 9 & Global driver \\
Corbet et al. & 105 & 3 & Hedging effectiveness \\
Nakamoto & 101 & 5 & Price fluctuation \\
Dwyer & 101 & 9 & Global driver \\
Kristoufek et al. & 88 & 10 & Investor reaction \\
Ciaian et al. & 85 & 3 & Hedging effectiveness \\
\hline
\end{tabular}

relative influences in the field of DC/EP. Dyhrberg ranks the first with 120 papers citing his work, followed by Baur et al. and Bouri et al. Four of them are from Cluster \#3. Both Cluster \#9 and Cluster \#10 have the two top-cited authors. The analysis indicates that the topic of "hedging effectiveness," "global driver," and "investor reaction" have drawn more research interest than others.

Further knowledge of the existing collaboration among authors can enhance productivity in DC/EP; therefore, we conduct a network analysis regarding authors and the resulted clusters are shown in Figure 9. Links show the existing collaboration among authors, and productive authors in the collaboration network are labeled. Our network of authors indicates that although the research in this emerging field by international scholars has not been highly collaborative, several partnership networks have been rising. For example, a four-node collaboration network exists among Zhang, Li, Shen, and Wang. Besides, Roubaud, Bouri, and Urquhart are also located in a highly collaborative network.

5.2. Core Countries and Collaboration Network. Papers published in the field of DC/EP can be clustered by country (region). Figure 10 shows the collaboration network of countries. It is clearly shown that the USA; several European countries such as France, England, and Germany; and Asian countries like China and South Korea have important positions in the network. Collaboration especially among the European countries is intense. Many nodes are surrounded by a purple ring, indicating a high betweenness centrality.

Table 9 summarizes the top ten countries in terms of the number of publications in the dataset. Among all the countries, the USA conducts the highest contribution in terms of the number of both published articles (88) and average citations (78). England ranks the second by the count of publications (49), while it is replaced by Canada regarding the average citations (34). China is also a productive country in DC/EP with a total publication of 41 . However, as to the average citations, it is the lowest of the ten countries at a level of 8 , which demonstrates that the studies from Chinese scholars have not attracted comparative attention. Nonetheless, some Chinese scholars only publish their papers in Chinese, which are omitted in the English database. Thus, interpretations based on English publications about China's role in global DC/EP research should be cautious. As to the centrality of these countries, France, Germany, and Canada rank the top three, while China and India are the lowest with a score of zero, indicating that the collaboration among the European countries is comparatively high, while China and India do DC/EP research independently and are not so involved into a global research network of DC/EP.

\section{Discussion on Limitations of This Study}

While this study summarizes and extends the knowledge bases on DC/EP, there are some limitations. First, selection bias is a common problem facing scientometric analysis [83]. For example, the references for this research were collected only from WoS, which limits the coverage of some recent relevant articles as well as working papers. Future research should use a wider range of databases to provide additional information on the trend analysis in recent years. To limit the scope of search among working papers, especially to identify those with relatively good quality, future scholars may consider focusing on the top economics and finance conferences as well as working papers of top financial research institutions.

Designing a good searching is indeed a big challenge for scientometric studies. Which terms or phrases should be used? How many terms should be searched? Using too many terms may cause a lot of irrelevant papers to be included and thus increase the computing burden for CiteSpace, while too little terms are likely to decrease the representativeness of scientometric studies. Keeping the balance between efficiency and representativeness is a trade-off for scientometric studies using CiteSpace at the current stage. Therefore, designing a robust metric or developing an approach for a good balance could be meaningful research in the future. Currently, we heavily rely on multiple rounds of experiments to find a good database for this study. In this study, we use topic searching that contains the information of title, abstract, keywords, and keywords plus and index-expansion strategy, which can retrieve the relevant articles as possible 


\begin{tabular}{|c|c|c|c|c|c|}
\hline No. & Keywords & Strength & Begin & End & $1995-2020$ \\
\hline 1 & Electronic payment & 9.1486 & 2000 & 2017 & 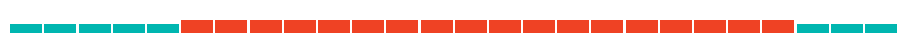 \\
\hline 2 & Information technology & 6.0394 & 2001 & 2017 & |مساس \\
\hline 3 & Model & 10.3311 & 2002 & 2013 & تصسمس \\
\hline 4 & Trust & 15.0737 & 2003 & 2013 & |ch \\
\hline 5 & Internet & 3.8902 & 2003 & 2017 & 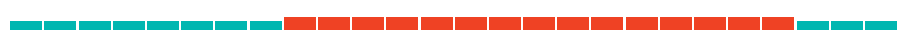 \\
\hline 6 & Behavior & 3.3634 & 2003 & 2018 & 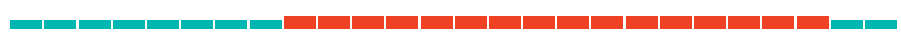 \\
\hline 7 & Determinant & 3.3548 & 2003 & 2016 & \\
\hline 8 & E commerce & 7.4437 & 2004 & 2011 & 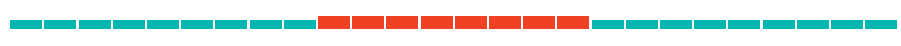 \\
\hline 9 & E-commerce & 4.7484 & 2004 & 2017 & טع \\
\hline 10 & Electronic commerce & 7.7192 & 2005 & 2008 & تصاس \\
\hline 11 & Consumer & 5.514 & 2006 & 2017 & بوس \\
\hline 12 & Impact & 4.691 & 2006 & 2015 & 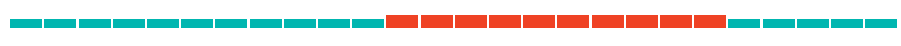 \\
\hline 13 & Adoption & 5.9756 & 2008 & 2017 & 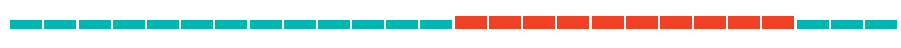 \\
\hline 14 & Retail payment & 3.5035 & 2010 & 2016 & 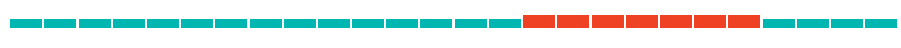 \\
\hline 15 & Cash & 6.1457 & 2013 & 2017 & בר \\
\hline 16 & Money & 4.1666 & 2015 & 2017 & تصاس \\
\hline 17 & Pay & 3.5385 & 2016 & 2017 & \\
\hline 18 & Digital currency & 5.5286 & 2017 & 2018 & \\
\hline
\end{tabular}

FiguRE 8: Keywords with the strongest citation bursts, ranked by the beginning year of burst.

CiteSpace, v. 5.6. R5 (64-bit)

June 6, 2020 5:23:37 PM CST

WoS: D: \User \Desktop $\backslash$ Review $\backslash$ bibreview $\backslash$ date

Timespan: 1995-2020 (Slice Length =1)

Selection Criteria: Top 100 per slice, $\mathrm{LRF}=3.0, \mathrm{LBY}=8, e=2.0$

Network: $N=56, E=48$ (Density $=0.0312$ )

Largest CC: 14 (25\%)

Nodes Labeled: $1.0 \%$

Pruning: Pathfinder

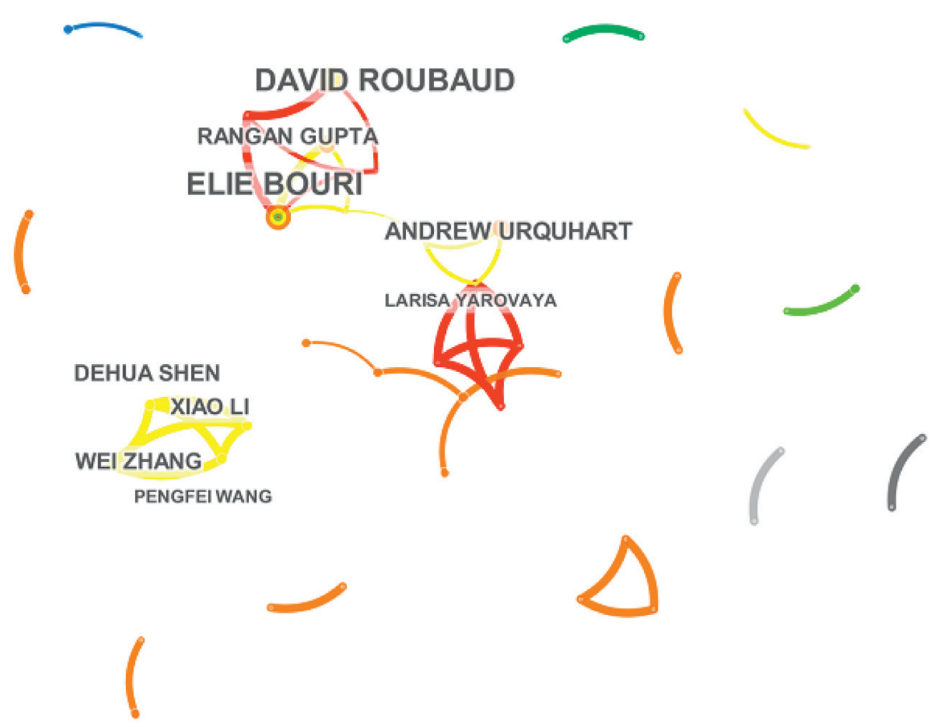

Figure 9: Collaboration of the authors in the field of DC/EP. 


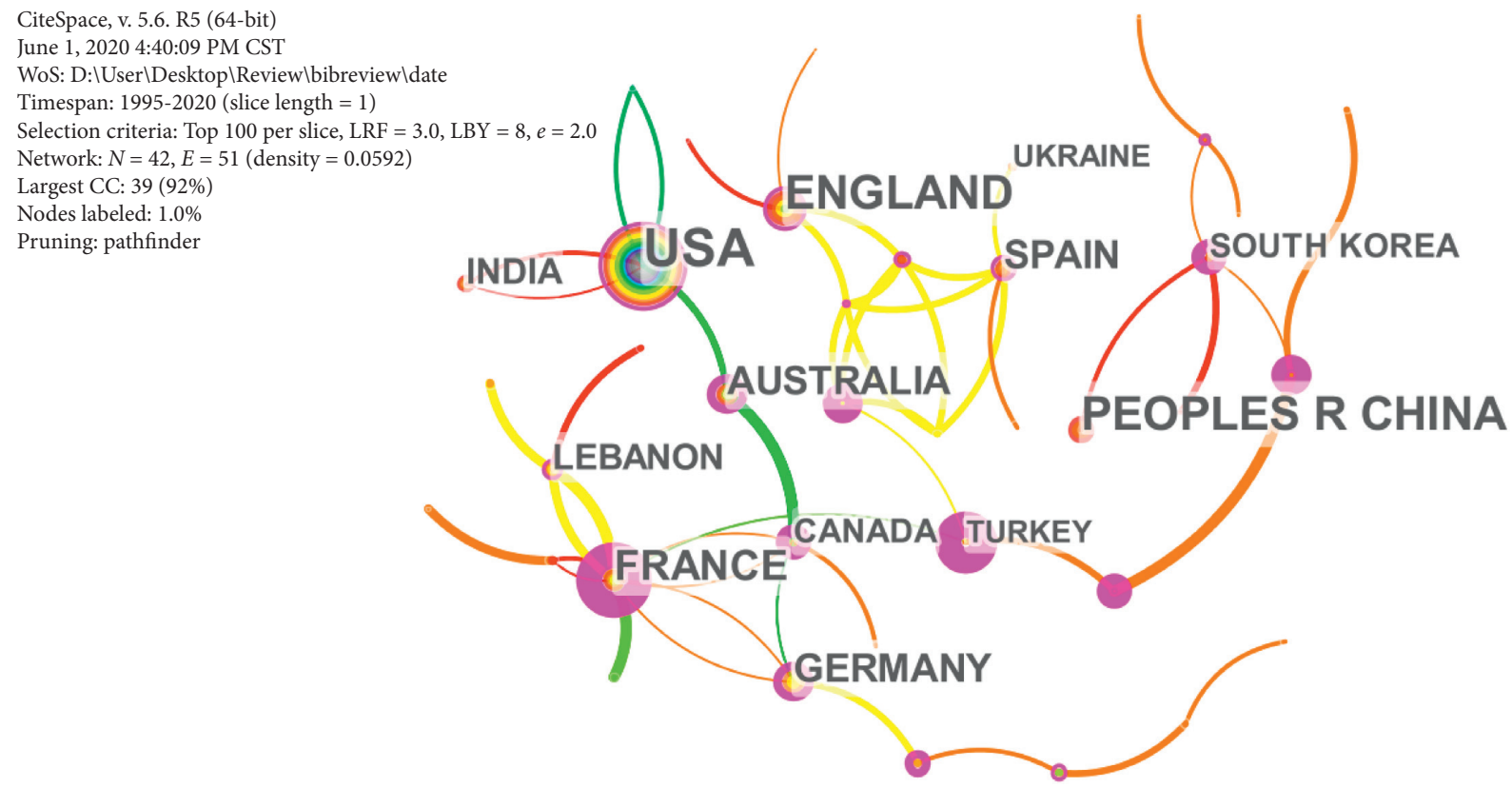

Figure 10: Network of countries in the field of DC/EP.

TABLE 9: Contributions of countries on DC/EP.

\begin{tabular}{lcccc}
\hline Country & Centrality & Counts & Total citations & Ave. citations \\
\hline USA & 0.18 & 88 & 6843 & 78 \\
England & 0.18 & 49 & 989 & 20 \\
PRC & 0.00 & 41 & 325 & 8 \\
France & 1.06 & 30 & 620 & 21 \\
Australia & 0.26 & 25 & 228 & 9 \\
Spain & 0.18 & 24 & 334 & 14 \\
Germany & 0.33 & 23 & 222 & 10 \\
India & 0.00 & 17 & 109 & 6 \\
Lebanon & 0.18 & 17 & 506 & 30 \\
Canada & 0.41 & 16 & 472 & 34 \\
\hline
\end{tabular}

as it could. Nonetheless, it is still impossible to collect all related papers. This kind of information loss is the necessary cost to bear for searching in scientometric studies.

Second, the algorithm used to perform the network analysis is predefined by the software according to the default rules of cocitation analysis, therefore less tailored discretion. Besides, CiteSpace requires the same ratio for the articles published at different time points. Thus, the most recent papers will not be included in the study sample, resulting in calculation inaccuracy, whose drawback is partly reduced in this study by analyzing the high coverage rate papers in major clusters.

\section{Conclusion and Future Research Remarks}

This study performs a scientometric study with the utilization of CiteSpace to obtain the knowledge bases and research frontiers in the field of DC/EP from the perspective of network analysis. Our main conclusions are as follows.

First, through network analysis of cited references, we construct a knowledge map of DC/EP including mainly eight clusters and visualize the development path. From the knowledge map and timeline visualization, two major clusters are selected, labeled as "Bitcoin-a hype" and "Volatility dynamics," respectively, with the log-likelihood algorithm. In terms of citation frequency and betweenness centrality, knowledge bases in this field are recognized, which could be classified into three main topics: (1) the usage and diversification effect of private digital currencies from the point of investment and asset allocation $[11,46,54,55]$; (2) the price dynamics and market efficiency of private digital currencies [48, 51-53, 56-58]; (3) other economic roles of digital currencies and corresponding change brought into the monetary system [47, 59].

Second, we study the evolution of the cocitation network based on a 5-year sliding window analysis. The modularity of these constructed networks exhibits sharp drops in the years 2003, 2010, and 2013, indicating structural changes may appear in the research trend. Combining with citation burst detection, we infer several research trends: (1) buyer's choice behavior of electronic transaction [65-67]; (2) the determinants of consumer's choice of different payment instruments [12, 68, 69]; and (3) how consumer's choice of payment instruments affects money demand and in turn affects bank's role [14, 70-72].

Third, the network of terms and keywords is analyzed. Ranked by recentness, four major clusters are derived. Combining with burst detection, we demonstrate two probable research fronts: (1) how social media and investor sentiment affect the market of digital currencies [74, 75]; (2) the impact of digital currencies on central bank, monetary policy, and central bank digital currency [80-82].

Finally, we identify core scholars and countries involved in the research of DC/EP and their collaboration networks. Dyhrberg ranks the first in terms of citing counts. At the 
country's level, the USA and France achieve the highest total local citation score and centrality, respectively. Academic collaboration in DC/EP has been rising, especially among the European scholars and countries.

With the results of our study, future research on DC/EP could make progress from several perspectives. First, while the roles of digital currencies in financial markets have been empirically studied, theoretical analysis of the underlying economic model is comparatively rare. More efforts should be devoted to expanding the scope of digital economic theory. Second, compared to digital currencies issued by private entities, central bank digital currency deserves further attention, especially the impact on modern monetary theory, international trade and payment, and cross-border collaboration.

\section{Data Availability}

The bibliographic records are retrieved from the Web of Science, and the processed data used to support the findings of this study are available at supplementary materials.

\section{Conflicts of Interest}

The authors declare that they have no conflicts of interest regarding this paper.

\section{Acknowledgments}

The authors appreciate the financial support from the Humanities and Social Sciences Foundation of the Ministry of Education of China (Grant no. 20YJC790110), the Basic and Applied Research Co-Foundation of Guangdong (Grant no. 2019A1515110693), and the National Natural Science Foundation of China (Grant no. 41901246).

\section{Supplementary Materials}

Data used for this study. (Supplementary Materials)

\section{References}

[1] C. Lagarde, Winds of Change: The Case for New Digital Currency, C. Department, Ed., p. 12, International Monetary Fund, Washington, DC, USA, 2019.

[2] L.-Y. Leong, T.-S. Hew, K.-B. Ooi, and A. Y.-L. Chong, "Predicting the antecedents of trust in social commerce-A hybrid structural equation modeling with neural network approach," Journal of Business Research, vol. 110, pp. 24-40, 2020.

[3] D. He, R. B. Leckow, V. Haksar et al., "Fintech and financial services: initial considerations," in Staff Discussion Notes, p. 49, International Monetary Fund, Washington, DC, USA, 2017.

[4] M. Raskin and D. Yermack, "Digital currencies, decentralized ledgers and the future of central banking," in Research Handbook on Central Banking, P. Conti-Brown, Ed., Edward Elgar Publishing, Cheltenham, UK, 2018.

[5] M. Swan, Blockchain: Blueprint for a New Economy, O’Reilly Media, Inc, Sebastopol, CA, USA, 2015.

[6] T. Mancini-Griffoli, M. M. Peria, I. Agur et al., "Casting light on central bank digital currencies," in Staff Discussion
Notesp. 39, International Monetary Fund, Washington, DC, USA, 2018.

[7] J. Chapman, R. Garratt, S. Hendry, A. McCormack, and W. McMahon, Project Jasper: Are Distributed Wholesale Payment Systems Feasible Yet?, Bank of Canada, Ottawa, Canada, 2017.

[8] S. Morris and H. S. Shin, Distributed Ledger Technology and Large Value Payments: A Global Game Approach, Princeton University, Princeton, NJ, USA, 2018.

[9] D. Duffie, "Digital currencies and fast payment systems," in Mimeo, Stanford University, Stanford, CA, USA, 2019.

[10] J. Carrick, "Bitcoin as a complement to emerging market currencies," Emerging Markets Finance and Trade, vol. 52, no. 10, pp. 2321-2334, 2016.

[11] E. Bouri, P. Molnár, G. Azzi, D. Roubaud, and L. I. Hagfors, "On the hedge and safe haven properties of bitcoin: is it really more than a diversifier?" Finance Research Letters, vol. 20, pp. 192-198, 2017.

[12] W. Bolt, N. Jonker, and C. van Renselaar, "Incentives at the counter: an empirical analysis of surcharging card payments and payment behaviour in the Netherlands," Journal of Banking \& Finance, vol. 34, no. 8, pp. 1738-1744, 2010.

[13] K. S. Rogoff, The Curse of Cash: How Large-Denomination Bills Aid Crime and Tax Evasion and Constrain Monetary Policy, Princeton University Press, Princeton, NJ, USA, 2017.

[14] D. He, "Monetary policy in the digital age," Finance and Development, vol. 55, no. 2, 2018.

[15] H. Hassani, X. Huang, and E. Silva, "Banking with blockchained big data," Journal of Management Analytics, vol. 5, no. 4, pp. 256-275, 2018.

[16] N. A. Plassaras, "Regulating digital currencies: bringing bitcoin within the reach of the IMF," Chicago Journal of International Law, vol. 14, no. 1, p. 26, 2013.

[17] B. Nelson, "Financial stability and monetary policy issues associated with digital currencies," Journal of Economics and Business, vol. 100, pp. 76-78, 2018.

[18] K. Hong, K. Park, and J. Yu, "Crowding out in a dual currency regime? Digital versus fiat currency," Emerging Markets Finance and Trade, vol. 54, no. 11, pp. 2495-2515, 2018.

[19] R. Böhme, N. Christin, B. Edelman, and T. Moore, "Bitcoin: economics, technology, and governance," Journal of Economic Perspectives, vol. 29, no. 2, pp. 213-238, 2015.

[20] F. Tschorsch and B. Scheuermann, "Bitcoin and beyond: a technical survey on decentralized digital currencies," IEEE Communications Surveys \& Tutorials, vol. 18, no. 3, pp. 2084-2123, 2016.

[21] M. Holub and J. Johnson, "Bitcoin research across disciplines," The Information Society, vol. 34, no. 2, pp. 114-126, 2018.

[22] S. Corbet, B. Lucey, A. Urquhart, and L. Yarovaya, "Cryptocurrencies as a financial asset: a systematic analysis," International Review of Financial Analysis, vol. 62, pp. 182-199, 2019.

[23] N. Dashkevich, S. Counsell, and G. Destefanis, "Blockchain application for central banks: a systematic mapping study," IEEE Access, vol. 8, pp. 139918-139952, 2020.

[24] C. Chen, "Science mapping: a systematic review of the literature," Journal of Data and Information Science, vol. 2, no. 2 , pp. 1-40, 2017.

[25] H. D. White and K. W. McCain, "Visualizing a discipline: an author co-citation analysis of information science, 19721995," Journal of the American Society for Information Science, vol. 49, no. 4, pp. 327-355, 1998. 
[26] H. Small, "Co-citation in the scientific literature: a new measure of the relationship between two documents," Journal of the American Society for Information Science, vol. 24, no. 4, pp. 265-269, 1973.

[27] M. Callon, J.-P. Courtial, W. A. Turner, and S. Bauin, "From translations to problematic networks: an introduction to coword analysis," Social Science Information, vol. 22, no. 2, pp. 191-235, 1983.

[28] M. J. Grant and A. Booth, "A typology of reviews: an analysis of 14 review types and associated methodologies," Health Information \& Libraries Journal, vol. 26, no. 2, pp. 91-108, 2009.

[29] C. M. Chen, CiteSpace: A Practical Guide for Mapping Scientific Literature, Nova Science Publishers, Hauppauge, NY, USA, 2016.

[30] I. Y. Wuni, G. Q. P. Shen, and R. Osei-Kyei, "Scientometric review of global research trends on green buildings in construction journals from 1992 to 2018," Energy and Buildings, vol. 190, pp. 69-85, 2019.

[31] L. Yu, G. Wang, and D. W. Marcouiller, "A scientometric review of pro-poor tourism research: visualization and analysis," Tourism Management Perspectives, vol. 30, pp. 7588, 2019.

[32] J. L. Ruiz-Real, J. Uribe-Toril, and J. C. Gazquez-Abad, "Destination branding: opportunities and new challenges," Journal of Destination Marketing \& Management, vol. 17, p. 13, 2020.

[33] Y. Yang and G. F. Meng, "The evolution and research framework of carbon footprint: based on the perspective of knowledge mapping," Ecological Indicators, vol. 112, p. 16, 2020.

[34] A. Andrikopoulos and G. Trichas, "Publication patterns and coauthorship in the journal of corporate finance," Journal of Corporate Finance, vol. 51, pp. 98-108, 2018.

[35] B. Burton, S. Kumar, and N. Pandey, "Twenty-five years of the European Journal of Finance (EJF): a retrospective analysis," The European Journal of Finance, p. 25, 2020.

[36] X. Gao, H. An, W. Fang, H. Li, and X. Sun, "The transmission of fluctuant patterns of the forex burden based on international crude oil prices," Energy, vol. 73, pp. 380-386, 2014.

[37] J. Shi and J. Malik, "Normalized cuts and image segmentation," IEEE Transactions on Pattern Analysis and Machine Intelligence, vol. 22, no. 8, pp. 888-905, 2000.

[38] C. Chen, F. Ibekwe-SanJuan, and J. Hou, "The structure and dynamics of cocitation clusters: a multiple-perspective cocitation analysis," Journal of the American Society for Information Science and Technology, vol. 61, no. 7, pp. 1386-1409, 2010.

[39] M. E. J. Newman and M. Girvan, "Finding and evaluating community structure in networks," Physical Review E, vol. 69, no. 2, p. 15, 2004.

[40] C. Chen, Z. Hu, S. Liu, and H. Tseng, "Emerging trends in regenerative medicine: a scientometric analysis in CiteSpace," Expert Opinion on Biological Therapy, vol. 12, no. 5, pp. 593-608, 2012.

[41] P. J. Rousseeuw, "Silhouettes: a graphical aid to the interpretation and validation of cluster analysis," Journal of Computational and Applied Mathematics, vol. 20, pp. 53-65, 1987.

[42] J. Kleinberg, "Bursty and hierarchical structure in streams," Data Mining and Knowledge Discovery, vol. 7, no. 4, pp. 373-397, 2003.

[43] C. M. Chen, "Detecting and mapping thematic changes in transient networks," in Proceedings of the Eighth International
Conference on Information Visualisation, 2004. IV 2004, E. Banissi, Ed., IEEE Computer Society, London, UK, pp. 1023-1032, July 2004.

[44] T. O. Olawumi and D. W. M. Chan, "A scientometric review of global research on sustainability and sustainable development," Journal of Cleaner Production, vol. 183, pp. 231-250, 2018.

[45] B. Lin and T. Su, "Mapping the oil price-stock market nexus researches: a scientometric review," International Review of Economics \& Finance, vol. 67, pp. 133-147, 2020.

[46] A. H. Dyhrberg, "Hedging capabilities of bitcoin. is it the virtual gold?” Finance Research Letters, vol. 16, pp. 139-144, 2016.

[47] G. Selgin, "Synthetic commodity money," Journal of Financial Stability, vol. 17, pp. 92-99, 2015.

[48] E.-T. Cheah and J. Fry, "Speculative bubbles in bitcoin markets? an empirical investigation into the fundamental value of Bitcoin," Economics Letters, vol. 130, pp. 32-36, 2015.

[49] G. P. Dwyer, "The economics of bitcoin and similar private digital currencies," Journal of Financial Stability, vol. 17, pp. 81-91, 2015.

[50] A. Urquhart, "The inefficiency of bitcoin," Economics Letters, vol. 148, pp. 80-82, 2016.

[51] S. Nadarajah and J. Chu, "On the inefficiency of bitcoin," Economics Letters, vol. 150, pp. 6-9, 2017.

[52] A. F. Bariviera, "The inefficiency of Bitcoin revisited: a dynamic approach," Economics Letters, vol. 161, pp. 1-4, 2017.

[53] P. Katsiampa, "Volatility estimation for Bitcoin: a comparison of GARCH models," Economics Letters, vol. 158, pp. 3-6, 2017.

[54] D. G. Baur, K. Hong, and A. D. Lee, "Bitcoin: medium of exchange or speculative assets?" Journal of International Financial Markets, Institutions and Money, vol. 54, pp. 177-189, 2018.

[55] E. Platanakis and A. Urquhart, "Should investors include bitcoin in their portfolios? a portfolio theory approach," The British Accounting Review, vol. 52, no. 4, p. 19, 2019.

[56] J. Alvarez-Ramirez, E. Rodriguez, and C. Ibarra-Valdez, "Long-range correlations and asymmetry in the bitcoin market," Physica A: Statistical Mechanics and Its Applications, vol. 492, pp. 948-955, 2018.

[57] P. Ciaian, M. Rajcaniova, and D. A. Kancs, "The economics of bitcoin price formation," Applied Economics, vol. 48, no. 19, pp. 1799-1815, 2016.

[58] A. Phillip, J. S. K. Chan, and S. Peiris, "A new look at cryptocurrencies," Economics Letters, vol. 163, pp. 6-9, 2018.

[59] T. Kim, "On the transaction cost of bitcoin," Finance Research Letters, vol. 23, pp. 300-305, 2017.

[60] P. Bedi and T. Nashier, "On the investment credentials of bitcoin: a cross-currency perspective," Research in International Business and Finance, vol. 51, p. 21, 2020.

[61] W. M. A. Ahmed, "Is there a risk-return trade-off in cryptocurrency markets? the case of bitcoin," Journal of Economics and Business, vol. 108, p. 21, 2019.

[62] L. Charfeddine, N. Benlagha, and Y. Maouchi, "Investigating the dynamic relationship between cryptocurrencies and conventional assets: implications for financial investors," Economic Modelling, vol. 85, pp. 198-217, 2020.

[63] A. Klarin, "The decade-long cryptocurrencies and the blockchain rollercoaster: mapping the intellectual structure and charting future directions," Research in International Business and Finance, vol. 51, p. 16, 2020.

[64] C. Chen, "Predictive effects of structural variation on citation counts," Journal of the American Society for Information Science and Technology, vol. 63, no. 3, pp. 431-449, 2012. 
[65] P. M. Doney and J. P. Cannon, "An examination of the nature of trust in buyer-seller relationships," Journal of Marketing, vol. 61, no. 2, pp. 35-51, 1997.

[66] D. Gefen, "E-commerce: the role of familiarity and trust," Omega, vol. 28, no. 6, pp. 725-737, 2000.

[67] S. Ba and P. A. Pavlou, "Evidence of the effect of trust building technology in electronic markets: price premiums and buyer behavior," MIS Quarterly, vol. 26, no. 3, pp. 243-268, 2002.

[68] S. Schuh and J. Stavins, "Why are (some) consumers (finally) writing fewer checks? the role of payment characteristics," Journal of Banking \& Finance, vol. 34, no. 8, pp. 1745-1758, 2010.

[69] J. Zinman, “Debit or credit?” Journal of Banking \& Finance, vol. 33, no. 2, pp. 358-366, 2009.

[70] A. T. Ching and F. Hayashi, "Payment card rewards programs and consumer payment choice," Journal of Banking \& Finance, vol. 34, no. 8, pp. 1773-1787, 2010.

[71] S. Carbó-Valverde and J. M. Liñares-Zegarra, "How effective are rewards programs in promoting payment card usage? empirical evidence," Journal of Banking \& Finance, vol. 35, no. 12, pp. 3275-3291, 2011.

[72] E. Klee, "How people pay: evidence from grocery store data," Journal of Monetary Economics, vol. 55, no. 3, pp. 526-541, 2008.

[73] P. He, L. Huang, and R. Wright, "Money, banking, and monetary policy," Journal of Monetary Economics, vol. 55, no. 6, pp. 1013-1024, 2008.

[74] S. Zhang, X. Zhou, H. Pan, and J. Jia, "Cryptocurrency, confirmatory bias and news readability-Evidence from the largest Chinese cryptocurrency exchange," Accounting \& Finance, vol. 58, no. 5, pp. 1445-1468, 2019.

[75] P. Xie, J. Wu, and $\mathrm{H}$. Du, "The relative importance of competition to contagion: evidence from the digital currency market," Financial Innovation, vol. 5, no. 1, p. 19, 2019.

[76] L. Rognone, S. Hyde, and S. S. Zhang, "News sentiment in the cryptocurrency market: an empirical comparison with forex," International Review of Financial Analysis, vol. 69, p. 17, 2020.

[77] O. Entrop, B. Frijns, and M. Seruset, "The determinants of price discovery on bitcoin markets," Journal of Futures Markets, vol. 40, no. 5, pp. 816-837, 2020.

[78] T. Takaishi, "Rough volatility of bitcoin," Finance Research Letters, vol. 32, p. 8, 2020.

[79] S. J. H. Shahzad, E. Bouri, D. Roubaud, and L. Kristoufek, "Safe haven, hedge and diversification for G7 stock markets: gold versus bitcoin," Economic Modelling, vol. 87, pp. 212224, 2020.

[80] S. Dow, "Monetary reform, central banks, and digital currencies," International Journal of Political Economy, vol. 48, no. 2, pp. 153-173, 2019.

[81] U. Bindseil, "Central bank digital currency: financial system implications and control," International Journal of Political Economy, vol. 48, no. 4, pp. 303-335, 2019.

[82] M. Hampl and T. Havranek, "Central bank equity as an instrument of monetary policy," Comparative Economic Studies, vol. 62, no. 1, pp. 49-68, 2020.

[83] Y. A. Su, Y. N. Yu, and N. Zhang, "Carbon emissions and environmental management based on big data and streaming data: a bibliometric analysis," Science of the Total Environment, vol. 733, p. 11, 2020. 